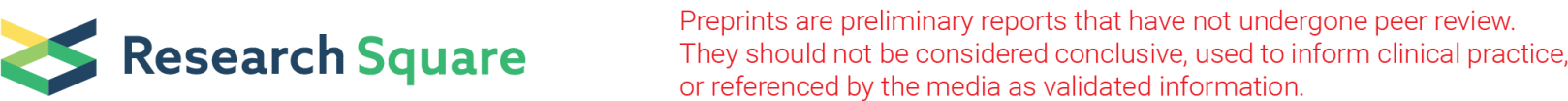

\section{Thetha Nami. Participatory development of a peer- navigator intervention to deliver biosocial HIV prevention for adolescents and young men and women in rural South Africa}

Maryam Shahmanesh ( $\sim$ m.shahmanesh@ucl.ac.uk)

University College London Institute for Global Health https://orcid.org/0000-0001-7129-8535

Nonhlanhla Okesola

Africa Health Research Institute

Natsayi Chimbindi

Africa Health Research Institute

Thembelihle Zuma

Africa Health Research Institute

Sakhile Mdluli

Africa Health Research Institute

Nondumiso Mthiyane

Africa Health Research Institute

Oluwafemi Adeagbo

Africa Health Research Institute

Jaco Dreyer

Africa Health Research Institute

Carina Herbst

Africa Health Research Institute

Sakhile Mdluli

Africa Health Research Institute

Nuala McGrath

University of Southampton

Guy Harling

University College London

Lorraine Sherr

University College London

Janet Seeley

London School of Hygiene and Tropical Medicine 


\section{Research article}

Keywords: HIV, health promotion, Peer-led, community-based participatory research, South Africa, PreExposure Prophylaxis, sexual health, adolescents, young people

Posted Date: July 21 st, 2020

DOI: https://doi.org/10.21203/rs.3.rs-42209/v1

License: (c) (i) This work is licensed under a Creative Commons Attribution 4.0 International License. Read Full License

Version of Record: A version of this preprint was published at BMC Public Health on July 13th, 2021. See the published version at https://doi.org/10.1186/s12889-021-11399-z. 


\section{Abstract}

\section{Background}

Despite effective biomedical tools, adolescents and young men and women carry the dual burden of high HIV incidence and high morbidity/mortality in South Africa. We integrated community-based participatory research (CBPR) with biomedical interventions to develop a peer-led biosocial intervention for HIV care and prevention in young people living in rural KwaZulu-Natal (KZN).

\section{Methods}

Between March 2018 and September 2019 we used CBPR to iteratively co-create and contextually adapt a biosocial peer-led intervention to support HIV prevention. Men and women aged 18-30 years were selected by community leaders of 21 intervention implementation areas (izigodi) and underwent 20 weeks of training as peer-navigators. We synthesised quantitative and qualitative data collected between 2016 and 2018 into 17 vignettes illustrating the local drivers of HIV. During two participatory intervention development workshops and community mapping, the peer-navigators discussed the vignettes in small groups, brainstormed solutions and mapped the components to their own izigodi. The intervention components were plotted to a Theory of Change (ToC). Following a six-month pilot, the peer-navigators used process evaluation data and experience to refine the ToC in a third workshop.

Results

Following written and oral assessments 57 of the 108 initially selected participated in the two workshops to discuss the vignettes and co-create the Thetha Nami (talk to me) intervention. During the pilot the peernavigators approached 6871 young people, of whom 6141 (89\%) accepted health promotion and 438 linked to care. During semi-structured interviews peer-navigators described the appeal of providing sexual health information to peers of a similar age and background but wanted to provide more than just "onward referral". In the third participatory workshop 54 peer-navigators refined the Thetha Nami intervention to include:

- Structured assessment tool to tailor support.

- Safe spaces and community advocacy to create an enabling environment for HIV prevention.

- Peer-led sexual health promotion to improve self-efficacy and demand for HIV prevention.

- Accessible youth-friendly clinical services to improve uptake of HIV prevention.

- Peer-mentorship to navigate resources and improve retention in HIV prevention.

Conclusion 
Local youth were able to use evidence to develop a contextually adapted peer-led intervention to deliver biosocial HIV prevention and care.

\section{Background}

South Africa (SA) has an estimated 7.7 million people living with HIV - the highest number globally; HIV remains the leading cause of death. HIV incidence has remained stubbornly high, especially in KwaZuluNatal (KZN) where we have shown an annual incidence of $8 \%$ amongst females aged $20-24$ and $4 \%$ in males aged 25-29 [1]. This is despite highly efficacious and cost-effective HIV prevention tools. These include HIV point-of-care tests (POCT) and self-tests; the use of daily oral tenofovir/emtricitabine for PreExposure Prophylaxis (PrEP), which can reduce the risk of acquiring HIV by up to $90 \%$; voluntary medical male circumcision that reduces the risk for men of acquiring HIV by $60 \%$; and HIV treatment with antiretroviral therapy (ART) that reduces mortality and eliminates onward transmission of HIV to sexual partners [2-4].

This failure to end the HIV epidemic is partly a result of the disparity between the vulnerability of subpopulations to HIV and their access to and uptake of HIV care and prevention tools. Adolescents and youth are one such subpopulation that is vulnerable due to a number of factors acting at multiple levels: Societal, familial, intimate-partnerships, individual behavioural, and biological [5]. This ultimately leads them to carry the dual burden of high HIV incidence and high mortality and morbidity due to delayed access to HIV testing and care [6]. Concern about young people's vulnerability to HIV-infection has led to the launch of initiatives, such as the DREAMS (determined, resilient, empowered, mentored and safe) partnership that combine social and behavioural interventions to reduce adolescent and youth vulnerability [7].

This combination of HIV interventions struggled to adequately integrate the biomedical and sociobehavioural components, partly because the public-sector health system has not been effective in linking young men and non-pregnant young women to HIV care [8,9]. The challenge of linkage was also found across the HIV treatment as prevention trials with young people, in particular men aged 25-35, missing from the treatment cascade [10-12]. There have been similar challenges to delivering PrEP to young people. First, while PrEP is efficacious in preventing HIV acquisition, low levels of adherence resulted in no observed benefit in PrEP trials among women in SA. Subsequent PrEP demonstration projects have consistently found it a challenge to retain young women in programmes $[13,14]$. Retention is likely to be an even greater challenge in rural settings where health systems are already struggling to deliver sexual and reproductive health services to young women [15].

Community-based care has been shown to optimise access and support adherence. Systematic reviews have found that: a) community-based delivery of HIV care (e.g., adherence clubs, community health workers) improved both ART uptake and retention in low and middle-income settings and were cost effective [16, 17]; and b) peers were effective in supporting ART adherence and virologic suppression, including amongst adolescents [18]. Nevertheless, none of these promising approaches have been 
rigorously tested in adolescents and young adults for the delivery of biomedical HIV prevention (e.g., PrEP) [19].

Community-based participatory research (CPPR) that places community members at the centre of the research process, provides a fora to listen and respond to the community, and the infrastructure to support community leadership and advocacy development, has been effective in generating relevant knowledge whilst supporting social change [20]. Such methods have been less frequently or consistently applied with young people, due to their limited social and political capital [21, 22]. We hypothesise that placing young people at the centre of the intervention development process, listening and responding to their concerns through careful and well supported CBPR, will provide a mechanism to co-create and contextually adapt effective biosocial interventions to tackle the HIV epidemic in sub-saharan Africa. The aim of this paper is to describe the process of participatory community development of Thetha Nami ("talk to $m e$ " in isiZulu), a biosocial peer-led intervention to integrate biomedical, behavioural and social components to improve the demand, uptake and retention in the cascades of HIV care and prevention and reduce the burden of HIV in young people living in rural KwaZulu-Natal, South Africa [3].

\section{Methods}

Between March 2018 and September 2019, we used CBPR to iteratively co-create and contextually adapt a biosocial intervention to be delivered by community-based peer-navigators. We used a logic model to show how and why the components of the intervention were theorized to improve demand, uptake and retention along the HIV prevention cascade (Theory of Change), in an area of rural KwaZulu-Natal, South Africa with high HIV incidence rates.

\section{Setting}

This study was conducted in the Africa Health Research Institute (AHRI) population-based intervention area in the uMkhanyakude district of KwaZulu-Natal, South Africa. The study area of $\sim 500 \mathrm{~km}^{2}$ with a population of $\sim 1700016-29$ year-olds was the site of the scale-up of structural and behavioural interventions through the DREAMS partnership between 2016 and 2018 [7]. The study area is mostly rural and poorer than most other parts of South Africa, with high levels of unemployment and a high burden of HIV $[1,9,23]$.

\section{Ethics}

Ethics approval was received by the Biomedical Research Ethics Committee (BREC BFC515/18) of the University of KwaZulu-Natal, South Africa and the REC (Rec numbers (5672/002) of University College London, United Kingdom.

\section{Participatory intervention development}


The process followed six steps in which through listening and responding to young people a biosocial intervention iteratively emerged (Fig. 1).

Step 1: Community engagement to identify and train youth to co-create and deliver the intervention: With the support of the AHRI community advisory board and public engagement unit (PEU), local traditional and municipal leadership from the 21 administrative areas (izigodi) were asked to identify $4-5$ young men and women living in their area who were aged 18-30 years to undergo 20 weeks of training and then work 24 hours per week to support youth in their areas. The criteria for selection that were developed with the AHRI PEU were that the youth had to: be aged 18-30; have completed high school and matriculated; and be actively engaged in their communities and considered opinion leaders [24]. We strongly encouraged leadership to suggest both young men and women. Participants underwent training which covered, youth development, HIV and sexual health information, accredited HIV counselling and testing course, confidentiality, ethics, and research methods. The training had originally been planned for 16 weeks. Progress was evaluated using written and oral assessments to select $\sim 55$ area-based peernavigators to co-create and implement the intervention.

Step 2: Synthesise the existing evidence of structural, behavioural and biological drivers of HIV: We used quantitative and qualitative data from the evaluation of the local scale-up of structural and behavioural interventions through the DREAMS partnership between 2016 and 2018 to summarise the structural, behavioural and biological drivers of HIV, and of engagement with the HIV prevention cascade. The evaluation data arose from: (i) surveys with a representative sample of 13-35-year-old-males and females ( $n=4918)$; (ii) rapid ethnographic community mapping $(n=4)$; (iii) provider and user interviews $(n=22$ and $n=58$ respectively); and (iv) group discussions $(n=29)$. Detailed methods and findings of the contextual factors that drive risk and create barriers to effective HIV testing, care and prevention have been previously reported $[1,6,9,15,25-28]$. For the purposes of the intervention development the findings were summarised and converted into vignettes, case-studies and simple infographics by a team of social scientists, statisticians and clinicians who had been engaged in the data collection and peernavigator training.

Step 3: Participatory workshop to develop the logic model for the theory of change (ToC). During a full day participatory workshop, participants were divided into mixed gender small groups of 6-8 individuals. Each group was moderated by social scientists. Participants had clear instructions to emerge from the groupwork with interventions they could implement. They used the vignettes as a vehicle to brainstorm practical approaches to mitigate the particular structural, behavioural and biological drivers of HIV and poor engagement with HIV care that the vignette signified. The candidate interventions were then plotted to a Theory of Change (ToC) (Fig. 2).

Step 4 Community entry and mapping the delivery of intervention components to each area (izigodi): The peer navigators were divided into three groups who each worked closely with one social scientist and a support team of clinicians (professional nurses) and social scientists. Each group: i) physically mapped the health, education and social services within their own communities (including introduction to the 
primary healthcare staff and community care givers in their areas); ii) mapped the places that young people gather; iii) identified potential adult youth champions to support them; iv) piloted the data collection tools; v) implemented the health promotion intervention under the supervision and observation of their supervisors; and vi) identified places for youth-friendly mobile healthcare services (Isisekelo Sempilo ('Foundation of Life" in isiZulu). They then came together in a second workshop to harmonize approaches in each izigodi.

Step 5: Pilot of the intervention and process evaluation. The intervention was piloted across the 21 izigodi with some of the larger or more densely populated areas having more than one pair of peer navigators. We conducted a process evaluation of the pilot using a combination of routine data, data collected from the training and supervision and semi-structured interviews with a purposive sample of peer-navigators. We collated data from anonymised programme data records from the peer navigators' daily reporting of their outreach activities. This included date and time, age, gender, area of recruitment, the peer navigator ID and the service provided by the peer navigator. This was supplemented with notes taken by the social science supervisors from bi-weekly training sessions, and weekly supervisory debriefings to assess the feasibility and acceptability of the intervention. Semi-structured interviews were conducted between April and August 2019 with 34 Thetha Nami peer navigators aged $20-30$ years ( 24 female and 10 male). The interviews were conducted in IsiZulu by a different team of social scientists, audio-recorded, transcribed and later translated to English. Participants' views were explored about the acceptability and feasibility of Thetha Nami intervention and interviews lasted between 30 to 60 minutes. Interview transcripts were managed and coded using NVIVO software and data were analysed thematically following an interpretivist approach. Initial findings reported here were derived from reflexive notes from the field to iteratively feed into step 6.

\section{Step 6: Participatory intervention development workshops to refine the intervention and ToC. We} conducted a third participatory workshop to discuss and rank the challenges to implementation and refine the intervention and ToC (Fig. 3) - in preparation for an effectiveness trial. Peer navigators were presented with the process evaluation findings and asked to reflect on their own experiences. They were divided into three moderated groups and asked to identify the challenges and rank their top three. They then deconstructed each challenge, described what its signified and brainstormed potential solutions. These were then presented pictorially and presented back to the whole group.

\section{Results}

Step 1: Community engagement to identify and train youth to co-create and deliver the intervention . Between March 2018 and June 2018, the traditional and municipal leadership identified 42 men and 66 women as potential peer-navigators. All 21 areas were able to identify around five youth who fitted the inclusion criteria and agreed to participate. The success of recruitment was partly because of the enthusiasm the community leaders expressed for a programme that provided both training and potentially employment to youth in their communities. 
Between June and September 2018 participants underwent a 20-week training programme (3 days a week). The training had originally been planned for 16 weeks, but due to the low levels of sexual and reproductive health knowledge was extended by 4 weeks. Fifty-seven peer-navigators were selected to implement the intervention; although the plan had been to select male-female pairs, only 13 of the 57 people selected by the assessments and interviews were men. Retention was good with 53 (92\%) still working after one year; of which $12(23 \%)$ were men, and 19 (36\%) aged $18-24$. All four who left the programme took up full time work or education. 
Table 1

Drivers of risk and barriers to effective uptake of multi-level HIV prevention for adolescents and young adults in rural KZN

\section{Unmet need Consequences of unmet need and challenges} vulnerability of youth

Sexual health needs
Social

- High unemployment (85\% of school-leavers are unemployed)

- Migration (30\% moved location in past year)

- Transactional sex (13\% in past year)

- $20 \%$ of women and $10 \%$ of men had a curable STI.

- $75 \%$ of these reporting no symptoms,

- $40 \%$ of the women had bacterial vaginosis.

- Home-based self-sampling and treatment for STIs was acceptable and desirable to young people

- Teenage pregnancy levels are persistently high, with an annual incidence of teenage pregnancy of $6.4 \%(5.7-8.6)$ (unpublished data)

- The majority of young women 15-24 start contraception after their first pregnancy.

- Poor sexual health and knowledge despite the importance of fertility

Unmet mental health needs

Challenges to uptake of HIV prevention interventions
- High levels of common mental disorders (CMD) which increase with age (rising to $32 \%$ of those aged $20-22$ ).

- Multiple service providers

- Increasing uptake of community-based interventions (social asset building; community mobilisation and parenting programmes) over the two year period

- Less success in reaching older adolescents, those out of school, and those who move

- Young boys felt excluded - apart from Voluntary Medical Male Circumcision.

- Limited uptake of regular HIV testing-Despite over $94 \%$ knowing where to get ART and wide-spread availability of free point of care HIV testing $<50 \%$ of $15-24$-year olds tested for HIV within the previous 12 months, with pregnancy being the strongest predictor of HIV-testing in women.

- Poor uptake of HIV care: $<20 \%$ of men aged $15-30$ who tested positive linked to care.

- Social costs (time and cost of travel, waiting times, stigma and attitude of health care providers to adolescent sexuality) of HIV testing and care outweighing any perceived benefits. 


\section{Unmet need Consequences of unmet need and challenges}

Sources of youth resilience
- Access to good sexual and reproductive health information

- Supportive network of peers, schools, and family members

- Social cohesion that support hope, a sense of belonging and altruism

- Interventions that were consistent and re-enforced existing cultural and social norms

\section{Step 2: Synthesise evidence of the structural, behavioural and biological drivers of HIV: and poor}

engagement Table 1 summarises the key drivers of risk and barriers to uptake of HIV care and prevention in our setting that were developed into 17 vignettes.

\section{Step 3: Participatory intervention development workshops to develop the logic model for the Theory of} Change. The first iteration of the intervention that was co-created through discussion of the 17 vignettes in the first workshop (June 2018); this process is shown in the phase 1 ToC (Fig. 2). The approach was that area-based Thetha Nami peer-navigators would increase the demand and motivation for HIV prevention by: i) fostering (community-level) positive social norms and resilience through recreation activities and support of youth champions- defined as adults in the area who engage in activities that support youth and/or are sympathetic to youth needs (e.g. youth leaders, teachers, and organisers of sport and other youth recreation); and ii) supporting (individual-level) sexual health literacy through promotion of sexual health information and education and condom provision to adolescents and young people aged 15-30 during peer outreach. Thetha Nami peer-navigators would increase uptake and retention in HIV prevention and care through: i) assessing youth needs and helping them navigate the mapped services; and ii) referals to accessible youth-friendly healthcare that provides HIV-status-neutral care integrated with sexual health.

Step 4: Community entry and mapping the intervention components to the areas: Between November 2018 and February 2019 the peer navigators worked with the social scientists and professional nurses to successfully enter and map all 21 izigodis and conducted a second workshop to harmonize activities (November 2018). Peer navigators were introduced to all the schools in 20 areas (91\%) and identified adult youth champions in 20 areas (91\%). They were able to identify sites for Isisekelo Sempilo clinics youth-friendly mobile healthcare services in all 21 areas. The Isisekelo Sempilo clinics, were developed in response to the need for accessible youth-friendly healthcare that provides HIV-status-neutral care integrated with sexual health. Together with the peer navigators and community leaders we identified two accessible and busy urban and peri-urban primary health care clinics and mobile clinic sites that were closely aligned with the local primary health care clinic. The mobile and fixed clinics were then established to deliver nurse-led pregnancy testing; family planning support; syndromic management for sexual and reproductive tract infections and if male referral to voluntary male medical circumcision. The 
clinics provided HIV counselling and point of care testing; antiretroviral therapy initiation if testing positive, and HIV PrEP if testing negative and eligible according to SA national guidelines.

Step 5: Pilot of the intervention and process evaluation. The Thetha Nami peer-navigator intervention was piloted between March 2019 and September 2019. Peer-navigators organised three activities (two music festivals and one soccer tournament) attended by 156 young people (aged 15-30) in total. The events were designed to create a safe space for youth to discuss sexual and reproductive health (sexually transmitted infections, HIV and teenage pregnancy) with peer navigators and clinical staff. Over six months, peer navigators logged reaching 6871 of the 16,473 (42\%) 15-30-year-old men and women living in their areas through outreach work. 6141 (89\%) accepted a rapid psychosocial and health needs assessment. Based on the assessments, the following needs were identified: referral or support for health needs, $n=2790$; social welfare needs, $n=435$; social vulnerability, $n=236$; educational (skills) support need, $n=2330$; and legal and advocacy support, $n=338$. Peer navigators distributed 41,450 male condoms, 3000 female condoms and 5898 HIV self-test kits, and provided 4145 information packs and referrals to Isisekelo Sempilo clinics; 438 (11\%) attended clinic

Semi-structured interviews with peer navigators suggested that they found young people were comfortable to share health-related issues, mostly sexual health and condom use, that they would not have shared with adults and appreciated the wider support (e.g., education services, CV writing). However, the peer-navigators were anxious that their young age was a barrier to being taken seriously by older adolescents, or, when the health information they promoted conflicted with the messages young people were receiving from their caregivers e.g. PrEP which was perceived to encourage young people to have sex.. They also felt inadequate when they could only refer participants to existing and sometimes unpopular services.

Step 6: Participatory intervention development workshops to refine the ToC: In September 2019 we conducted the third participatory workshop with 54 peer navigators. Peer navigators identified their highest-ranked challenges as: Thetha Nami not being valued by youth; Youth being lazy to engage with the Isisekelo Sempilo clinics; and HIV stigma. First they deconstructed what these challenges signified:

1. Thetha Nami being seen as "useless by youth". Peer navigators identified this as partly due to the logistic barriers they faced in delivering Thetha Nami: small age differences particularly with older adolescents; lack of safe spaces for youth to gather; and size of the rural areas with poor transport links. However, on reflection they identified this "uselessness" as signifying gaps in the services they had at their disposal to offer youth. In particular they were concerned that they lacked concrete social welfare and employability services to refer participants to and were reliant on referring to existing and stretched government services.

2. Youth are "lazy" to engage with HIV testing and biomedical prevention and care. "Laziness" emerged as meaning "scared". They described this overwhelming fear amongst youth to test for HIV because they are scared to know their HIV status, scared to find out they are HIV seropositive, and then scared to disclose to their families. When reflecting on their frustration at the apparent failure of their 
positive messaging and provision of adolescent friendly convenient services to mitigate this "scaredness" they identified two further challenges: (i) the novelty of messaging around HIV treatment rendering individual uninfectious ("Undetectable = Untransmissible" or “ $U=U$ ") and PrEP both for the peer navigators and community members - slowed promotion within communities; and (ii) the resistance from caregivers and elders to these novel interventions that were perceived to "encourage" adolescent sexual activity.

3. HIV stigma. Stigma was seen as a result of fear: internal fear, i.e. things young people feared would happen to them if they tested HIV-positive; and external fear, i.e., things young people thought others would say or do to them if they were known to have HIV or be at risk of HIV. Internal stigma and fear around HIV were seen to be fueled by some of the persistent beliefs surrounding HIV. For example, that HIV treatment is arduous (e.g. the need to have food with ART, having to take ART the same time every day, not being able to mix alcohol with ART), and the anticipated negative psychological effect of knowing their status; described as "killing"them. External HIV stigma was fueled by others seeing them as "dirty, immoral and infectious" and not worthy of being in a "healthy sexual relationship".

The groups then brainstormed adaptations to the Thetha Nami intervention to tackle these challenges. These were mapped to a revised ToC (Fig. 3):

i. Adapt the tablet-based psychosocial and health needs assessment tools to tailor health promotion plans for ongoing peer-mentorship and support to young people.

ii. Identify and create safe and non-judgmental fixed spaces in each community which young people can gather and receive sexual and reproductive health information, socialize and engage in activities.

iii. Develop youth groups with structured skill building to improve employability and/or enterprise, e.g. investment and saving schemes, starting small businesses.

iv. Develop simpler " $U=U$ " and sexual health messaging that peer navigators can promote when they meet youth

v. Enhance sexual health promotion with screening for reproductive tract infections

vi. Promote the same " $U=U$ " and sexual health messaging more widely with youth champions and parents/carers, and through advocacy with local political and traditional leadership.

Thetha Nami Peer-led biosocial intervention: The final co-created Thetha Nami intervention that will be evaluated consists of area-based peer-navigators working to increase the demand and motivation for HIV prevention by: i) fostering positive social norms and resilience through youth-groups with structured skills-building; ii) safe spaces and recreation activities; iii) creating an enabling environment for youth through community-wide health promotion; iv) youth champions and advocacy with the local political institutions; and v) supporting (individual-level) promotion of HIV prevention that is tailored to need and pivots around sexual health literacy and mentorship to support self-efficacy. Peer-navigators would increase uptake and retention in HIV prevention and care through: i) mapping the health, education and 
social services within their own communities; ii) provision of accessible youth-friendly healthcare that provides HIV status neutral care within an enhanced sexual health service; and iii) provide ongoing tailored peer-support and lay counselling of young people to retain them in care.

\section{Discussion}

Using evidence of what worked for young people like them, local youth were able to design and develop a theoretically informed peer-led intervention to deliver a biosocial intervention that strengthens the cascade of HIV prevention and can potentially improve well-being. Young people were able to engage creatively with the evidence and contextually adapt effective interventions to this rural and deprived setting. Moreover, roll out of this area-based peer-navigators intervention for HIV prevention with adolescents and youth was acceptable and reached more than one in three of the target group over a sixmonth period.

Thetha Nami explicitly tackled the challenges young people found in identifying themselves as candidates for the biomedical HIV care and prevention [26] through two mechanisms; first by emphasizing a HIV status neutral health promotion message that pivoted around sexual health. Second by removing structural barriers to accessing care by delivering accessible and youth friendly clinical services and tackling community norms around adolescent sexuality. Whilst Thetha Nami has features in common with the HIV status neutral approaches in high income settings [29] and calls to integrate PrEP with sexual health services [13], the use of community-based participatory research enabled the peernavigators to adapt the biosocial intervention to their own rural setting. Moreover, by using the needs assessment tool to tailor health promotion they can differentiate support at an individual level, with those with greater need receiving the greatest amount of peer support [30,31].

Through the participatory process the peer-navigators identified the need for community wide interventions; safe spaces and peer mentorship to support a protective environment. The Thetha Nami emergent intervention is thus theoretically aligned with the protection-risk framework [32,33] advocated to improve adolescent well-being. Whilst the Thetha Nami components are similar to combination prevention interventions such as DREAMS [7] by using community-based participatory research they are informed by a social justice framework and are explicitly led by the young people for whom the intervention is meant [21]. The emphasis on youth leadership and equity as the key ingredient to both intervention design and delivery, places Thetha Nami closer to the successful combination interventions that emerged from sex worker mobilization and collectivization a decade earlier [30] .

In this area of high youth unemployment, the peer-navigator intervention was seen as beneficial not only to the community but also the peer navigators themselves by providing training, work and income. The benefits of participating in peer mentorship programmes on the peers themselves has been described in other programmes [31] and suggests the Thetha Nami programme can be a vehicle to accelerate some of the sustainable development goals amongst adolescents [34]. 
Our study show that internalised and externalised HIV stigma and social norms around adolescent and youth sexuality remain a huge challenge to delivering HIV prevention, even in these high HIV burden rural settings [35-37]. Young people involved in this research brought a nuanced understanding of the intersection between poverty and lack of opportunity, and the gender and intergenerational power imbalances to the intervention development process $[38,39]$. The solution they proposed is a youth-led intervention to organise and mobilise other young people to challenge social norms and lack of opportunity, and access healthcare within their own locality. However, the hypothesis that this will reduce HIV stigma, empower youth and change social norms remains to be tested.

With increasing need for long-term prevention in well people within universal health care, developing effective and efficient models of community delivery of care for the growing number of young people entering adolescence, such as the one we describe here is increasingly important not just for HIV but wider adolescent health [40]. Thetha Nami has been developed to be sustainable through community caregiver programs that are widely involved in healthcare delivery in southern Africa. However, the effectiveness and cost effectiveness of this peer-led biosocial intervention to reduce HIV-related mortality and morbidity and improve sexual health outcomes and well-being will need to be tested in a randomized controlled trial.

\section{Conclusion}

- Community-based participatory research methods are powerful and feasible ways to develop, contextually adapt and deliver interventions in partnership with young people.

- Extensive training and time are required to support participatory research methods.

- Gender and HIV status neutral approach were strengths.

- Early challenges highlighted the intergenerational power imbalances and the need for advocacy alongside the intervention delivery.

\section{Declarations}

\section{Ethical approval and consent to participate}

All participants in the study were provided with study information and provided written consent to participate in the study. Participants aged 18 and under informed consent was obtained from their parents or legal guardians and informed assent was obtained from the child prior to study enrolment. Ethics approval was received by the Biomedical Research Ethics Committee (BREC BFC515/18) of the University of KwaZulu-Natal, South Africa and the REC (Rec numbers (5672/002) of University College London, United Kingdom.

Consent for publication: Not applicable

\section{Availability of data and materials}


The datasets generated and/or analysed during the current study are available in the AHRI repository and will be made available prior to publication

The qualitative datasets used and/or analysed during the current study are available from the corresponding author on reasonable request.

\section{Competing interests:}

The authors declare that they have no competing interests

\section{Funding}

This work was supported by the National Institutes of Health under award number 5R01MH114560-03, Bill \& Melinda Gates Foundation, Grant Number OPP1136774 and OPP1171600. Africa Health Research Institute is supported by a grant from the Wellcome Trust (082384/Z/07/Z). The AHRI population surveillance is partially funded by DSI-MRC South Africa Population Research Network. GH is supported by a fellowship from the Wellcome Trust and Royal Society (210479/Z/18/Z).

\section{Authors' contributions:}

MS, conceived and designed the study and prepared the first and final draft of the manuscript, $\mathrm{NC}$ and $\mathrm{CH}$ managed the project, developed and piloted the data collection tools, training and implementation, NO recruited, trained and supervised the peer navigators. JS and LS supported the participatory methods used and analysis and interpretation of the qualitative findings. TZ and SM conducted and analysed the qualitative studies that fed into the participatory workshops, led the participatory workshops and development of the ToC; NM and GH led the quantitative analysis and interpretation that fed into the participatory workshops. JD led all aspects of data management, curating and quality control. OA led the process evaluation. All authors read and commented on iterartions of the manuscript and approved the final manuscript.

\section{Acknowledgements}

We thank the study participants, the Thetha Nami Peer Navigators and the research team at AHRI.

\section{References}

1. Chimbindi N, Mthiyane N, Birdthistle I, Floyd S, McGrath N, Pillay D, Seeley J, Zuma T, Dreyer J, Gareta D, et al. Persistently high incidence of HIV and poor service uptake in adolescent girls and young women in rural KwaZulu-Natal, South Africa prior to DREAMS. PLoS One. 2018;13(10):e0203193.

2. Garnett GP, Hallett TB, Takaruza A, Hargreaves J, Rhead R, Warren M, Nyamukapa C, Gregson S. Providing a conceptual framework for HIV prevention cascades and assessing feasibility of empirical measurement with data from east Zimbabwe: a case study. Lancet HIV. 2016;3(7):e297306. 
3. Hargreaves JR, Delany-Moretlwe S, Hallett TB, Johnson S, Kapiga S, Bhattacharjee P, Dallabetta G, Garnett GP. The HIV prevention cascade: integrating theories of epidemiological, behavioural, and social science into programme design and monitoring. Lancet HIV. 2016;3(7):e318-22.

4. Garnett GP, Krishnaratne S, Harris KL, Hallett TB, Santos M, Enstone JE, Hensen B, Dallabetta G, Revill P, Gregson SAJ, et al: Cost-Effectiveness of Interventions to Prevent HIV Acquisition. In: Major Infectious Diseases. edn. Edited by Holmes KK, Bertozzi S, Bloom BR, Jha P. Washington (DC); 2017.

5. Dellar RC, Dlamini S, Karim QA. Adolescent girls and young women: key populations for HIV epidemic control. J Int AIDS Soc. 2015;18(2 Suppl 1):19408.

6. Gourlay A, Birdthistle I, Mthiyane NT, Orindi BO, Muuo S, Kwaro D, Shahmanesh M, Baisley K, Ziraba A, Floyd S. Awareness and uptake of layered HIV prevention programming for young women: analysis of population-based surveys in three DREAMS settings in Kenya and South Africa. BMC Public Health. 2019;19(1):1417.

7. Birdthistle I, Schaffnit SB, Kwaro D, Shahmanesh M, Ziraba A, Kabiru CW, Phillips-Howard P, Chimbindi N, Ondeng'e K, Gourlay A, et al. Evaluating the impact of the DREAMS partnership to reduce HIV incidence among adolescent girls and young women in four settings: a study protocol. BMC Public Health. 2018;18(1):912.

8. Baisley KJ, Seeley J, Siedner MJ, Koole K, Matthews P, Tanser F, Barnighausen T, Smit T, Gareta D, Dlamini S, et al. Findings from home-based HIV testing and facilitated linkage after scale-up of test and treat in rural South Africa: young people still missing. HIV Med. 2019;20(10):704-8.

9. Baisley K, Chimbindi N, Mthiyane N, Floyd S, McGrath N, Pillay D, Seeley J, Zuma T, Dreyer J, Gareta D, et al. High HIV incidence and low uptake of HIV prevention services: The context of risk for young male adults prior to DREAMS in rural KwaZulu-Natal, South Africa. PLoS One. 2018;13(12):e0208689.

10. Iwuji CC, Orne-Gliemann J, Larmarange J, Balestre E, Thiebaut R, Tanser F, Okesola N, Makowa T, Dreyer $\mathrm{J}$, Herbst $\mathrm{K}$, et al. Universal test and treat and the HIV epidemic in rural South Africa: a phase 4, open-label, community cluster randomised trial. Lancet HIV. 2018;5(3):e116-25.

11. Bock P, Fatti G, Ford N, Jennings K, Kruger J, Gunst C, Louis F, Grobbelaar N, Shanaube K, Floyd S, et al. Attrition when providing antiretroviral treatment at CD 4 counts $>500$ cells $/ \mathrm{muL}$ at three government clinics included in the HPTN 071 (PopART) trial in South Africa. PLoS One. 2018;13(4):e0195127.

12. Hayes RJ, Donnell D, Floyd S, Mandla N, Bwalya J, Sabapathy K, Yang B, Phiri M, Schaap A, Eshleman SH, et al. Effect of Universal Testing and Treatment on HIV Incidence - HPTN 071 (PopART). N Engl J Med. 2019;381(3):207-18.

13. Celum CL, Delany-Moretlwe S, Baeten JM, van der Straten A, Hosek S, Bukusi EA, McConnell M, Barnabas RV, Bekker LG. HIV pre-exposure prophylaxis for adolescent girls and young women in Africa: from efficacy trials to delivery. J Int AIDS Soc. 2019;22(Suppl 4):e25298.

14. Haberer JE, Mugo N, Baeten JM, Pyra M, Bukusi E, Bekker LG. PrEP as a Lifestyle and Investment for Adolescent Girls and Young Women in Sub-Saharan Africa. Journal of the International Association 
of Providers of AIDS Care. 2019;18:2325958219831011.

15. Francis SC, Mthiyane TN, Baisley K, McHunu SL, Ferguson JB, Smit T, Crucitti T, Gareta D, Dlamini S, Mutevedzi T, et al. Prevalence of sexually transmitted infections among young people in South Africa: A nested survey in a health and demographic surveillance site. PLoS Med. 2018;15(2):e1002512.

16. Kanters S, Park JJ, Chan K, Socias ME, Ford N, Forrest JI, Thorlund K, Nachega JB, Mills EJ: Interventions to improve adherence to antiretroviral therapy: a systematic review and network metaanalysis. Lancet HIV 2017, 4(1):e31-e40.

17. Smith JA, Sharma M, Levin C, Baeten JM, van Rooyen H, Celum C, Hallett TB, Barnabas RV. Costeffectiveness of community-based strategies to strengthen the continuum of HIV care in rural South Africa: a health economic modelling analysis. Lancet HIV. 2015;2(4):e159-68.

18. Kanters S, Park JJ, Chan K, Ford N, Forrest J, Thorlund K, Nachega JB, Mills EJ. Use of peers to improve adherence to antiretroviral therapy: a global network meta-analysis. J Int AIDS Soc. 2016;19(1):21141.

19. Pettifor A, Nguyen NL, Celum C, Cowan FM, Go V, Hightow-Weidman L. Tailored combination prevention packages and PrEP for young key populations. J Int AIDS Soc. 2015;18(2 Suppl 1):19434.

20. Loewenson R, Laurell AC, Hogstedt C, D'Ambruoso L, Shroff Z: Participatory action research in health systems: a methods reader. : TARSC, AHPSR, WHO, IDRC Canada, Equinet; 2014.

21. Mannell J, Willan S, Shahmanesh M, Seeley J, Sherr L, Gibbs A. Why interventions to prevent intimate partner violence and HIV have failed young women in southern Africa. J Int AIDS Soc. 2019;22(8):e25380.

22. Bradbury-Jones C, Isham L, Taylor J. The complexities and contradictions in participatory research with vulnerable children and young people: A qualitative systematic review. Soc Sci Med. 2018;215:80-91.

23. Tanser F, Hosegood V, Barnighausen T, Herbst K, Nyirenda M, Muhwava W, Newell C, Viljoen J, Mutevedzi T, Newell ML. Cohort Profile: Africa Centre Demographic Information System (ACDIS) and population-based HIV survey. Int J Epidemiol. 2008;37(5):956-62.

24. Kelly JA. Popular opinion leaders and HIV prevention peer education: resolving discrepant findings, and implications for the development of effective community programmes. AIDS Care. 2004;16(2):139-50.

25. Zuma T, Seeley J, Sibiya LO, Chimbindi N, Birdthistle I, Sherr L, Shahmanesh M. The Changing Landscape of Diverse HIV Treatment and Prevention Interventions: Experiences and Perceptions of Adolescents and Young Adults in Rural KwaZulu-Natal, South Africa. Front Public Health. 2019;7:336.

26. Adeagbo O, Herbst C, Blandford A, McKendry R, Estcourt C, Seeley J, Shahmanesh M. Exploring People's Candidacy for Mobile Health-Supported HIV Testing and Care Services in Rural KwaZuluNatal, South Africa: Qualitative Study. J Med Internet Res. 2019;21(11):e15681. 
27. Chimbindi N, Birdthistle I, Shahmanesh M, Osindo J, Mushati P, Ondeng'e K, Zuma T, Chiyaka T, Kyegombe N, Hargreaves J, et al. Translating DREAMS into practice: Early lessons from implementation in six settings. PLoS One. 2018;13(12):e0208243.

28. Harling G, Gumede D, Shahmanesh M, Pillay D, Barnighausen TW, Tanser F. Sources of social support and sexual behaviour advice for young adults in rural South Africa. BMJ Glob Health. 2018;3(6):e000955.

29. Duncombe C, Ravishankar S, Zuniga JM. Fast-Track Cities: striving to end urban HIV epidemics by 2030. Curr Opin HIV AIDS. 2019;14(6):503-8.

30. Steen R, Zhao P, Wi TE, Punchihewa N, Abeyewickreme I, Lo YR. Halting and reversing HIV epidemics in Asia by interrupting transmission in sex work: experience and outcomes from ten countries. Expert Rev Anti Infect Ther. 2013;11(10):999-1015.

31. Mavhu W, Willis N, Mufuka J, Bernays S, Tshuma M, Mangenah C, Maheswaran H, Mangezi W, Apollo $T$, Araya R, et al. Effect of a differentiated service delivery model on virological failure in adolescents with HIV in Zimbabwe (Zvandiri): a cluster-randomised controlled trial. Lancet Glob Health. 2020;8(2):e264-75.

32. Donovan JE, Jessor R, Costa FM. Adolescent health behavior and conventionality-unconventionality: an extension of problem-behavior theory. Health Psychol. 1991;10(1):52-61.

33. Jessor R. Risk behavior in adolescence: a psychosocial framework for understanding and action. $J$ Adolesc Health. 1991;12(8):597-605.

34. Cluver LD, Orkin FM, Campeau L, Toska E, Webb D, Carlqvist A, Sherr L. Improving lives by accelerating progress towards the UN Sustainable Development Goals for adolescents living with HIV: a prospective cohort study. Lancet Child Adolesc Health. 2019;3(4):245-54.

35. Hargreaves JR, Krishnaratne S, Mathema H, Lilleston PS, Sievwright K, Mandla N, Mainga T, Vermaak R, Piwowar-Manning E, Schaap A, et al. Individual and community-level risk factors for HIV stigma in 21 Zambian and South African communities: analysis of data from the HPTN071 (PopART) study. AIDS. 2018;32(6):783-93.

36. Nkosi B, Seeley J, Ngwenya N, McHunu SL, Gumede D, Ferguson J, Doyle AM. Exploring adolescents and young people's candidacy for utilising health services in a rural district, South Africa. BMC Health Serv Res. 2019;19(1):195.

37. Velloza J, Khoza N, Scorgie F, Chitukuta M, Mutero P, Mutiti K, Mangxilana N, Nobula L, Bulterys MA, Atujuna $\mathrm{M}$, et al. The influence of HIV-related stigma on PrEP disclosure and adherence among adolescent girls and young women in HPTN 082: a qualitative study. J Int AIDS Soc. 2020;23(3):e25463.

38. Logie CH, Williams CC, Wang Y, Marcus N, Kazemi M, Cioppa L, Kaida A, Webster K, Beaver K, de Pokomandy $A$, et al. Adapting stigma mechanism frameworks to explore complex pathways between intersectional stigma and HIV-related health outcomes among women living with HIV in Canada. Soc Sci Med. 2019;232:129-38. 
39. Logie $\mathrm{CH}$, Okumu M, Mwima SP, Kyambadde P, Hakiza R, Kibathi IP, Kironde E, Musinguzi J, Kipenda CU. Exploring associations between adolescent sexual and reproductive health stigma and HIV testing awareness and uptake among urban refugee and displaced youth in Kampala, Uganda. Sex Reprod Health Matters. 2019;27(3):86-106.

40. Weiss HA, Ferrand RA. Improving adolescent health: an evidence-based call to action. Lancet. 2019;393(10176):1073-5.

\section{Figures}

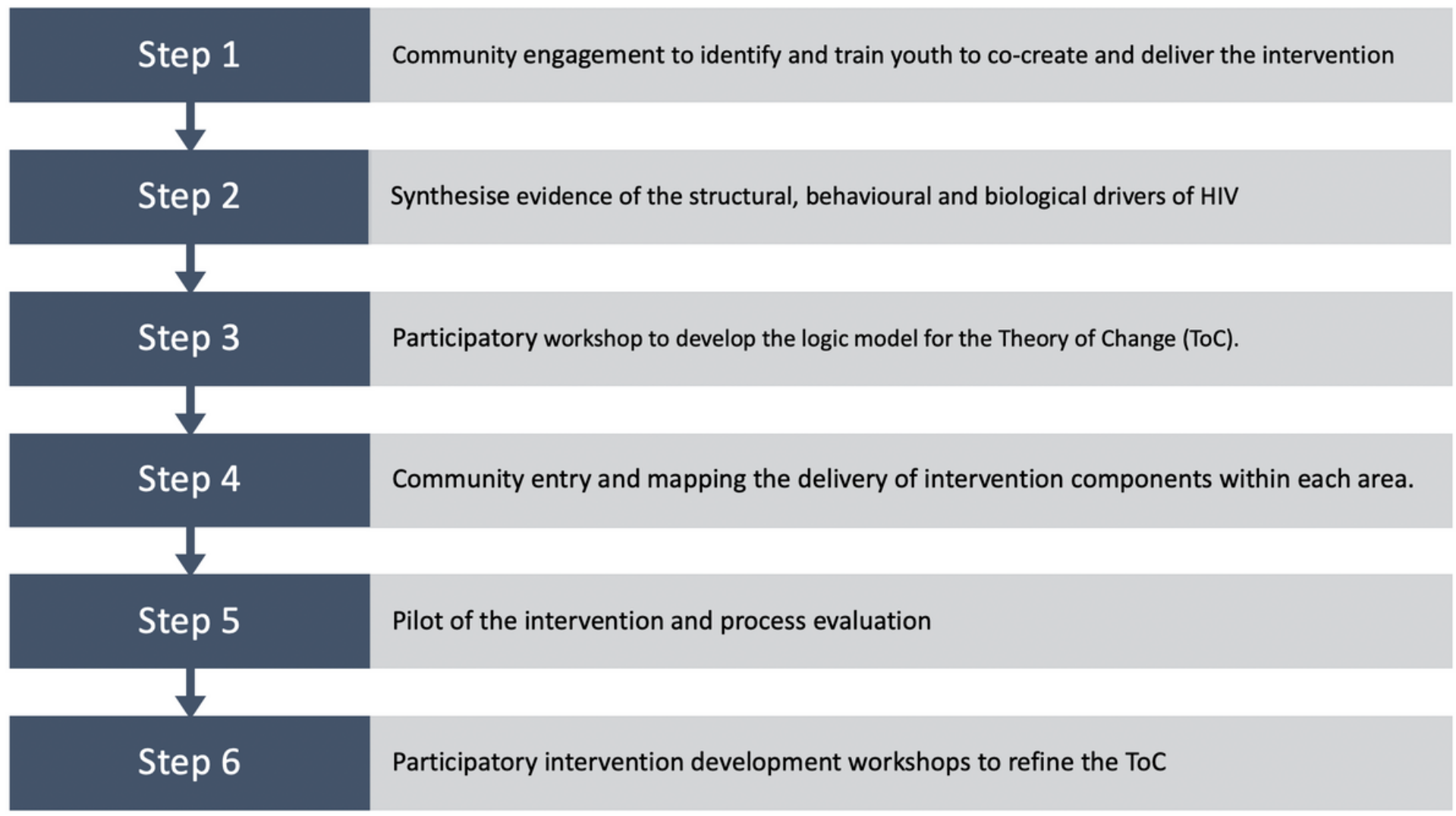

\section{Figure 1}

Steps to develop Thetha Nami participatory peer-led biosocial intervention 


\begin{tabular}{|c|c|c|c|c|c|}
\hline Level & Problems/ Mediators of risk & Input/ Activities (interventions) & Outputs & $\begin{array}{c}\text { Pathways to change } \\
\text { (intermediate outcomes) }\end{array}$ & $\begin{array}{l}\text { Long term } \\
\text { Goal }\end{array}$ \\
\hline Social & $\begin{array}{l}\text { - } \\
\text { - } \quad \text { Unempleynal stigma } \\
\text { - } \quad \text { Adolescent transition } \\
\text { - Lack of social cohesion } \\
\text { - Low retention in community } \\
\text { interventions }\end{array}$ & $\begin{array}{l}\text { - Identify local youth champions } \\
\text { - } \quad \text { Sport and recreation activities } \\
\text { - Map health and social services } \\
\text { Peer navigation of health and } \\
\text { social services }\end{array}$ & $\begin{array}{l}\text { - No. of youth champions identified } \\
\text { - No. of youth activities planned } \\
\text { - No. of youth that attend activities } \\
\text { - Proportion of peers navigator } \\
\text { pairs that mapped services }\end{array}$ & $\begin{array}{l}\text { - } \quad \text { Foster positive social norms } \\
\text { - Foster group efficacy and } \\
\text { resilience } \\
\text { - Improve uptake of existing } \\
\text { health, education and social } \\
\text { services }\end{array}$ & \multirow{3}{*}{$\begin{array}{l}\text { To improve } \\
\text { health and } \\
\text { wellbeing of } \\
\text { adolescents } \\
\text { and young } \\
\text { people living in } \\
\text { rural South } \\
\text { Africa through } \\
\text { reducing HIV } \\
\text { incidence and } \\
\text { HIV morbidity } \\
\text { and mortality }\end{array}$} \\
\hline Individual & $\begin{array}{l}\text { - Internalised stigma } \\
\text { - Low SRH knowledge } \\
\text { - Low uptake SRH and condoms } \\
\text { - Common mental disorders, } \\
\text { alcohol and transactional sex }\end{array}$ & $\begin{array}{ll}\text { - } & \text { Peer outreach to promote: } \\
\circ & \text { Sexual health knowledge } \\
\circ & \text { Distribute condoms } \\
\circ & \text { Promote U=U }\end{array}$ & $\begin{array}{l}\text { - No. of youth reached } \\
\text { - Proportion of youth approached } \\
\text { that accept peer support } \\
\text { - No. of condoms and information } \\
\text { packs distributed }\end{array}$ & $\begin{array}{l}\text { - Improve self efficacy } \\
\text { - Improved sexual health literacy } \\
\text { - Improve uptake of condoms and } \\
\text { HIV testing }\end{array}$ & \\
\hline Biological & $\begin{array}{l}\text { High proportion of young men } \\
\text { and women with a detectable } \\
\text { HIV viral load } \\
\text { - STIs and BV are common } \\
\text { - Low use of primary healthcare }\end{array}$ & $\begin{array}{l}\text { Provision of community-based } \\
\text { youth-friendly healthcare } \\
\text { - HIV status neutral approach } \\
\text { - Integrated sexual health and HIV } \\
\text { care (including PrEP) }\end{array}$ & $\begin{array}{l}\text { - No of youth referred to health } \\
\text { services } \\
\text { - Proportion referred that link to care } \\
\text { - Proportion linked that uptake family } \\
\text { planning, HIV treatment if positive } \\
\text { or PrEP if eligible and negative }\end{array}$ & $\begin{array}{l}\text { - Increase uptake of biomedical } \\
\text { interventions } \\
\text { - } \quad \text { Reduced proportion of young } \\
\text { people with a detectable HIV viral } \\
\text { load }\end{array}$ & \\
\hline
\end{tabular}

$\sum$

Figure 2

Thetha Nami peer-led biosocial intervention: Theory of Change (ToC) Phase 1

\begin{tabular}{|c|c|c|c|c|c|}
\hline Level & Problems/ Mediators of risk & Input/ Activities (interventions) & Outputs & $\begin{array}{c}\text { Pathways to change } \\
\text { (intermediate outcomes) }\end{array}$ & $\begin{array}{l}\text { Long term } \\
\text { Goal }\end{array}$ \\
\hline Social & $\begin{array}{l}\text { - External stigma } \\
\text { - Unemployment \& Mobility } \\
\text { - } \quad \text { Adolescent transition } \\
\text { - Lack of social cohesion } \\
\text { - Low retention in community } \\
\text { interventions }\end{array}$ & $\begin{array}{l}\text { - } \quad \text { Identify local youth champions } \\
\text { - } \quad \text { Sport and recreation activities } \\
\text { - } \quad \text { Map health and social services } \\
\text { - } \quad \text { Peer navigation of health and } \\
\text { - } \quad \text { Social services } \\
\text { Youth groups with structured } \\
\text { skill building } \\
\text { - Community advocacy } \\
\text { - Identify safe spaces }\end{array}$ & $\begin{array}{l}\text { - } \quad \text { No. of youth champions identified } \\
\text { - No. of youth activities planned } \\
\text { - } \quad \text { Po. of youth that attend activities } \\
\text { - } \quad \text { that mapped services } \\
\text { Proportion of peer navigators who } \\
\text { set up a youth group } \\
\text { - No. of peers that engage in advocacy } \\
\text { Proportion of areas that create a safe } \\
\text { space for youth }\end{array}$ & $\begin{array}{l}\text { - Foster positive social norms } \\
\text { - Foster group efficacy and } \\
\text { resilience } \\
\text { Improve uptake of existing } \\
\text { health, education and social } \\
\text { services } \\
\text { - Skills for employability } \\
\text { - Foster an enabling } \\
\text { environment }\end{array}$ & \multirow{3}{*}{$\begin{array}{l} \\
\\
\text { To improve } \\
\text { health and } \\
\text { wellbeing of } \\
\text { adolescents } \\
\text { and young } \\
\text { people living in } \\
\text { rural South } \\
\text { Africa through } \\
\text { reducing HIV } \\
\text { incidence and } \\
\text { HIV morbidity } \\
\text { and mortality }\end{array}$} \\
\hline Individual & $\begin{array}{l}\text { - Internalised stigma } \\
\text { - Low SRH knowledge } \\
\text { - Low uptake SRH and condoms } \\
\text { - Common mental disorders, } \\
\text { alcohol and transactional sex }\end{array}$ & $\begin{array}{ll}\text { - } & \text { Peer outreach promote: } \\
\circ & \text { Sexual health knowledge } \\
\circ & \text { Distribute condoms } \\
\circ & \text { Promote } U=U \\
\text { - } & \text { Peer-mentorship } \\
\text { - } & \text { Assessment tool to tailor } \\
& \text { health promotion and } \\
& \text { mentorship plans }\end{array}$ & $\begin{array}{l}\text { - No. of youth reached } \\
\text { - } \quad \text { acceportion of youth approached that } \\
\text { No. of condoms and information packs } \\
\text { distributed } \\
\text { Proportion of peers who meet } \\
\text { mentees at least four times per year }\end{array}$ & $\begin{array}{l}\text { - Improve self efficacy } \\
\text { - } \quad \text { Improved sexual health literacy } \\
\text { - Improve uptake of condoms } \\
\text { and HIV testing } \\
\text { - Ongoing support for sexual } \\
\text { health and HIV prevention }\end{array}$ & \\
\hline Biological & $\begin{array}{l}\text { - High proportion of young } \\
\text { men and women with a } \\
\text { detectable HIV viral load } \\
\text { - STIs and BV are common } \\
\text { - Low use of primary } \\
\text { healthcare }\end{array}$ & 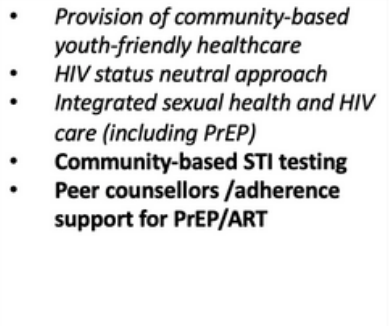 & $\begin{array}{l}\text { - No of youth referred to health services } \\
\text { - Proportion referred that link to care } \\
\text { - Proportion linked that uptake family } \\
\text { planning, HIV treatment if positive or } \\
\text { PrEP if eligible and negative } \\
\text { - Proportion retained in follow-up (at } \\
\text { least } 2 \text { visits per } 12 \text { months) } \\
\text { - No of STIs diagnosed and treated } \\
\text { - No. of youth on ART/PrEP/family } \\
\text { planning supported by peers in } \\
\text { community. }\end{array}$ & $\begin{array}{l}\text { - Increase uptake of biomedical } \\
\text { interventions } \\
\text { - Reduced proportion of young } \\
\text { people with a detectable HIV } \\
\text { viral load } \\
\text { - } \quad \begin{array}{l}\text { Reduce STIs } \\
\text { Increase retention in ART } \\
\text { based prevention }\end{array}\end{array}$ & \\
\hline
\end{tabular}

Figure 3 
Thetha Nami peer-led biosocial intervention: Theory of Change (ToC) Phase 